\title{
Factors Which Influence Intraluminal Temperature during Ho:YAG-Laser Exposure at an In-Vitro URS
}

\author{
Jens Cordes*, Felix Nguyen, Karl-Dietrich Sievert \\ Clinic of Urology, University Medical Center Schleswig-Holstein, Campus Lübeck, Lübeck, Germany \\ Email: Jens.Cordes@uk-sh.de
}

Received 12 March 2015; accepted 16 April 2015; published 17 April 2015

Copyright (C) 2015 by authors and Scientific Research Publishing Inc.

This work is licensed under the Creative Commons Attribution International License (CC BY). http://creativecommons.org/licenses/by/4.0/

(c) (i) Open Access

\section{Abstract}

Introduction: The Ho:YAG-Laser is categorized as a potentially dangerous lithotripsy device (DIN: Class 4) for perforation which is mainly caused by the photonic energy the laser emits. Long time complications like ureteral strictures seem to be directed by thermal and mechanical injury. In this study different energy settings a) are being investigated, a DJ (double J stent) is placed beside the laser to simulate a therapy of a forgotten stent with reduction of the lumen b) due to the volume exploitation of the DJ, and direct contact between the laser fiber and the DJ in the ureter c) is simulated during laser exposure. Materials and Methods: We used the Ho:YAG-laser (Vera Pulse ${ }^{\mathrm{TM}}$, Coherent, Santa Clara USA) with a $365 \mu \mathrm{m}$ diameter laser fiber. The settings of the laser were $0.6 \mathrm{~J}$ and $1 \mathrm{~J}$ pulse energy with a frequency of $5 \mathrm{~Hz}$. The experimental setup was closely aligned with the clinical situation. The tip of the thermometer was attached inside the catheter through a puncture. The laser fiber was guided by means of a rigid URS video device (11.5 Ch). We had four different settings for a), b) and c) during the measurement: 1) Distance of $0.5 \mathrm{~cm}$ between the laser and the thermometer; without irrigation, 2) Distance of $0.5 \mathrm{~cm}$ between the laser and the thermometer; with irrigation, 3) Distance of $1 \mathrm{~cm}$ between the laser and the thermometer; without irrigation, 4) Distance of $1 \mathrm{~cm}$ between the laser and the thermometer; with irrigation. Results: The temperature in an empty ureter rises approximately by $5^{\circ} \mathrm{C}$, when the laser energy is increased from $0.6 \mathrm{~J}$ to $1 \mathrm{~J}$. When a DJ is inserted in the artificial ureter there is surprisingly almost no difference in the maximum temperature between the lower energy level (0.6 J) and the high energy level (1 J). However the time needed to reach the maximum temperature is noticibly less when using high energy levels. The reduction involume based on the placement of the DJ leads to a higher maximum temperature for the low energy setting. The third setting with direct laser fiber contact with the DJ produces the highest temperatures of up to $55^{\circ} \mathrm{C}$. We think there must be a melting or burning of the DJ which leads to a temperature rise. Bubble formation was a sign of heating in the ureter in every setting without irrigation. A temperature fall off with increasing distance between

\footnotetext{
${ }^{*}$ Corresponding author.
} 
the laser fiber and the thermometer is noticable when measuring without irrigation. Conclusion: There is no relevant heating with irrigation. Direct contact between the laser fiber and the DJ seems to evoke additional heating because of melting or underwater burning of the DJ. The maximum temperatures reached without irrigation are limited to a relatively small volume since the is a noticable temperature fall of when increasing the distance between the laser fiber and the thermometer.

\section{Keywords}

YAG-Laser, URS, Laser Fiber, DJ, Ureteral

\section{Introduction}

In 2006, Urolithiasis is one of the main diagnoses in urology in Germany after diseases of the prostate [1]. 97\% of the stones were found in the ureter or kidney [2]. In a global study of the endourological society with 11,885 patients, $49 \%$ of the urologists used the laser as a fragmentation device beside the ureteroscopy (30.3\% pneumatic, $1.2 \%$ ultrasonic and $0.3 \%$ electrohydraulic) [3]. This distribution shows that the Ho:YAG-Laser is named correctly as the gold standard lithotripsy modality for endoscopic lithotripsy [4].

On the other hand, the Ho:YAG-Laser is categorized as a potentially dangerous lithotripsy device for perforation [5] which is mainly caused by the photonic energy the laser emits. Long time complications like ureteral strictures seem to be directed by thermal and mechanical injury [6]. So it is important to know the temperature profiles in the ureter under different conditions. The laser is a high energy instrument which can melt metals like nitinol [7]. In a first measurement in an artificial ureter Cordes et al. showed a maximal heating of $50^{\circ} \mathrm{C}$ during 60 seconds of laser exposure in an artificial ureter, without irrigation, a pulse energy of $0.6 \mathrm{~J}$ and a frequency of $5 \mathrm{~Hz}[8]$.

In this study we do the next step with different energy settings, a wider lumen of the artificial ureter, a DJ (Universa $^{\circledR}$, Soft, Standard, COOK ${ }^{\circledR}$, Bloomington, Indiana) beside the laser and URS-Device simulating a therapy of a forgotten stent and a direct contact of the laser fiber and the DJ during exposure.

\section{Material and Methods}

We used the Ho:YAG-laser (Versa Pulse ${ }^{\mathrm{TM}}$, Coherent, Santa Clara, USA) with a $365 \mu \mathrm{m}$ diameter laser fiber. Thepulse energy of the laser was either $0.6 \mathrm{~J}$ or $1 \mathrm{~J}$ with a frequency of $5 \mathrm{~Hz}$. The experimental setup was closely aligned with the clinical situation (Figure 1).

A metal container was filled with $0.9 \%$ sodium chloride $(\mathrm{NaCl})$ solution with a temperature of $36.8^{\circ} \mathrm{C}$ and a catheter (27 Ch, Bladder catheter, Couvelaire, Teleflex ${ }^{\circledR}$, Willy Rüsch GmbH, Kernen, Germany, Inner diameter $21 \mathrm{Ch}$ ) was attached to the rim of the container. The tip of the digital thermometer (Greifinger ${ }^{\circledR}$, Erolzheim, Germany) was attached inside the catheter through a puncture. The laser fiber was guided by means of a rigid URS video device (11.5 Ch).

The URS device (11.5 Ch, Richard-Wolf GmbH, Knittlingen, Germany) including the laser fiber was now inserted into the artificial ureter and located with a distance of both $0.5 \mathrm{~cm}$ and $1 \mathrm{~cm}$ to the tip of the thermometer (Figure 2).

During the measurements with irrigation, a $\mathrm{NaCl}$ solution was piped through the URS-device. The irrigation was hung up above the setup and had the same height of about $1.80 \mathrm{~m}$ from the ground as it is commonly used in our typical operation setup. The irrigation fluid came out of our warming facility with a temperature of $37^{\circ} \mathrm{C}$.

Three different temperature profiles at laser exposure were measured in:

1) An empty ureter;

2) An ureter equipped with a DJ;

3) With direct contact between the laser fiber and the DJ in the ureter.

In these 3 different settings we had four different variables during the measurement with pulse energy levels of $0.6 \mathrm{~J}$ and $1 \mathrm{~J}$ :

a) Distance of $0.5 \mathrm{~cm}$ between laser fiber and thermometer; without irrigation; 


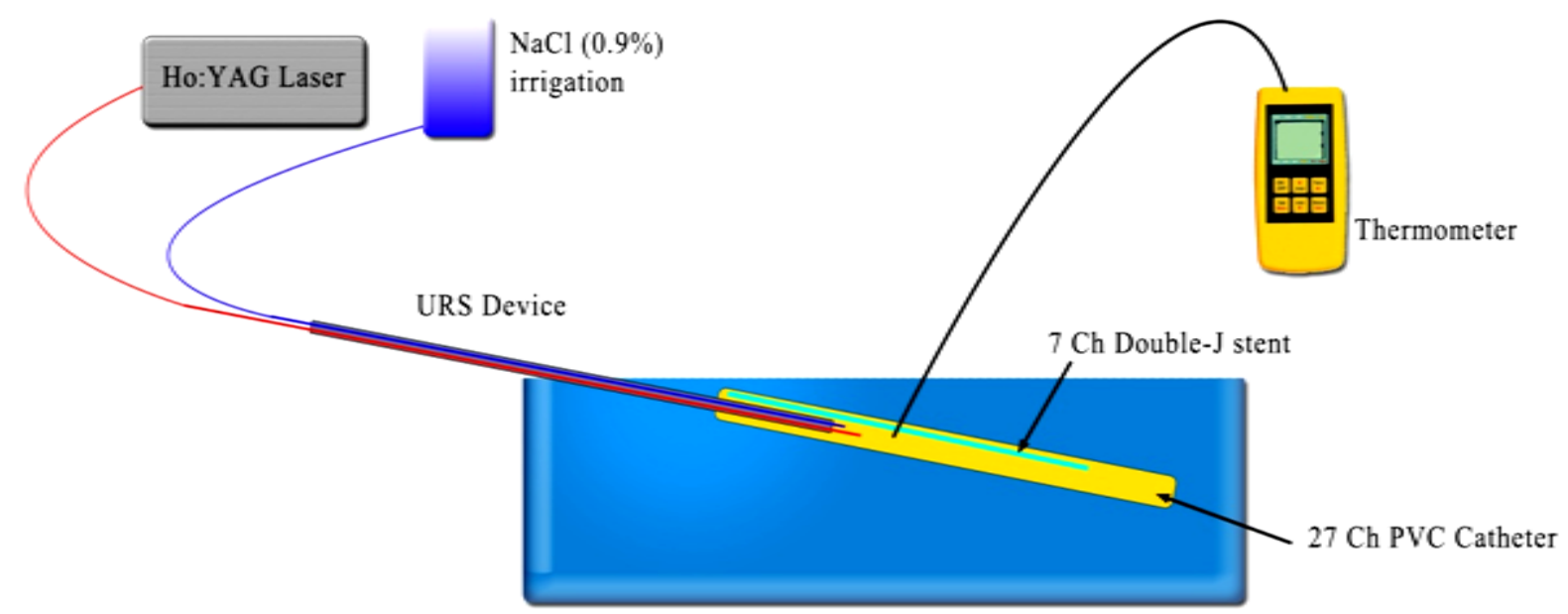

Pond filled with $\mathrm{NaCl} 0.9 \%$

Figure 1. The schematic drawing of the experimental setup shows the URS device including the laser fiber and the irrigation canal, the intraluminal tip of the thermometer and the Double-J stent inside a catheter surrounded by $\mathrm{NaCl}$ solution.

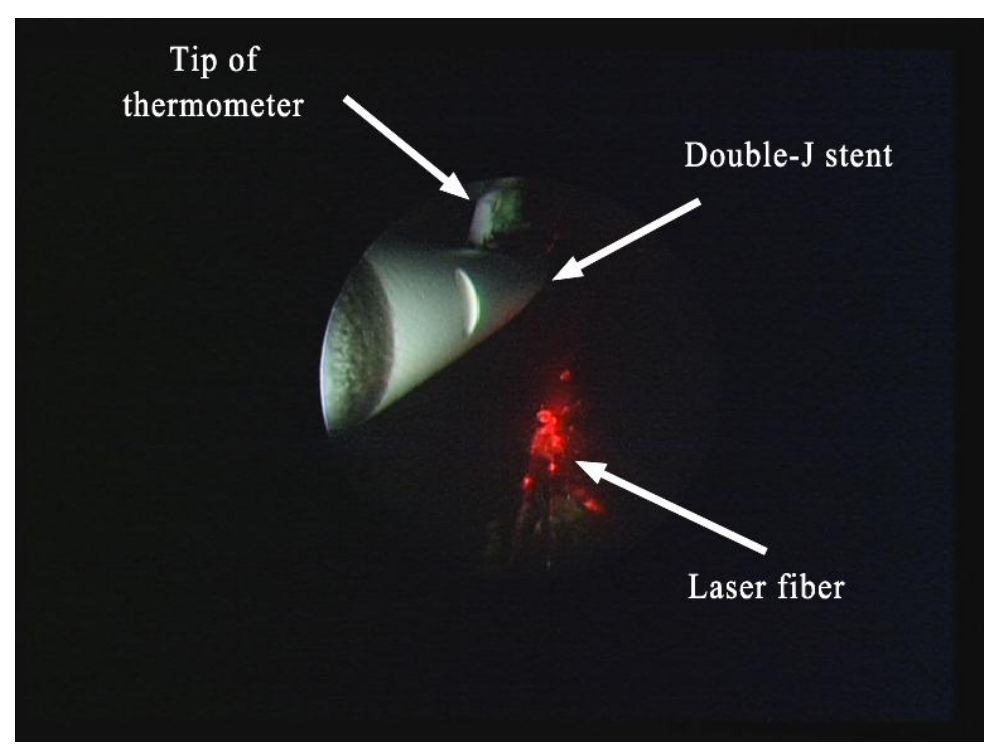

Figure 2. View from inside the catheter through the renoscope. The tip of the thermometer, the DJ and the laser fiber are visible.

b) Distance of $0.5 \mathrm{~cm}$ between laser fiber and thermometer; with irrigation;

c) Distance of $1 \mathrm{~cm}$ between laser fiber and thermometer; without irrigation;

d) Distance of $1 \mathrm{~cm}$ between laser fiber and thermometer; with irrigation.

\section{Results}

In the first setting with an empty ureter and a pulse energy of $0.6 \mathrm{~J}$ we had a maximal temperature of $40.5^{\circ} \mathrm{C}$ without irrigation and a distance of $0.5 \mathrm{~cm}$ to the thermometer. For a longer distance of $1 \mathrm{~cm}$ we had a temperature plateau about $35.1^{\circ} \mathrm{C}$ to $35.5^{\circ} \mathrm{C}$. We had no heating with continus irrigation (Figure 3).

With a pulse energy of $1 \mathrm{~J}$ we had a maximal temperature of $46.9^{\circ} \mathrm{C}$ without irrigation and a distance of 0.5 $\mathrm{cm}$ to the thermometer. We had a plateau of $33.5^{\circ} \mathrm{C}$ with a longer distance of $1 \mathrm{~cm}$. There was no heating with irrigation (Figure 4).

In conclusion it shows that a higher pulse energy level of $1 \mathrm{~J}$ could raise the heating in our setting about $6^{\circ} \mathrm{C}$. With irrigation there is no heating at all (Figure 3 and Figure 4). 


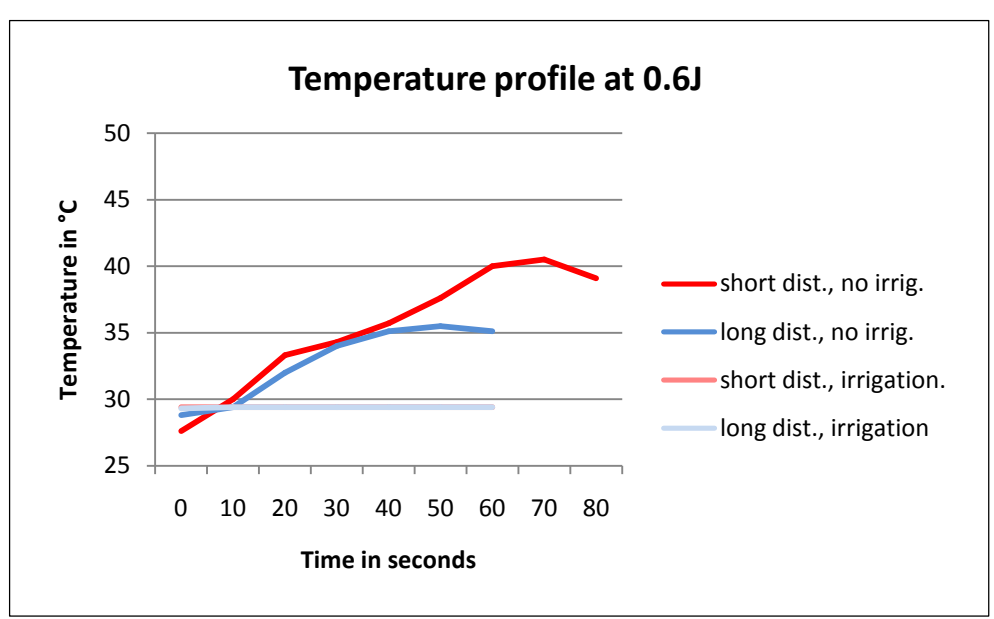

Figure 3. Temperature profile for a measurement with pulse energy of $0.6 \mathrm{~J}$ in an empty ureter with 4 different settings (short dist. irrigation is behind long dist. irrigation).

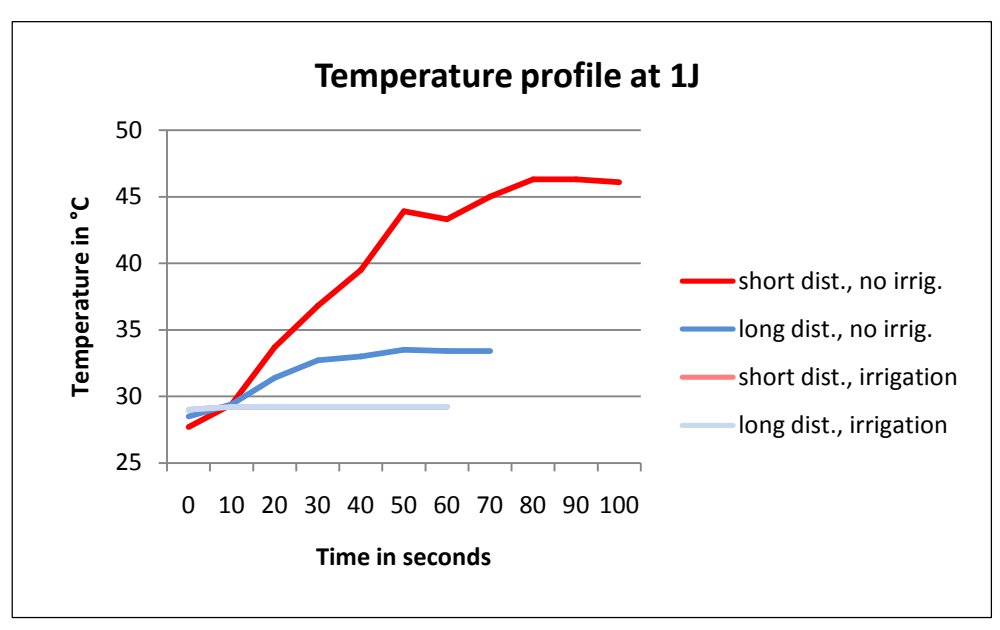

Figure 4. Temperature profile for a measurement with pulse energy of $1 \mathrm{~J}$ in an empty ureter with 4 different settings (short dist. irrigation is behind long dist. irrigation).

In the second experiment the artificial ureter was equipped with a DJ and the energy setting was set to $0.6 \mathrm{~J}$. The maximal temperature was about $43.5^{\circ} \mathrm{C}$ without irrigation with a short distance of $0.5 \mathrm{~cm}$ between the laser fiber and the thermometer. A higher distance of $1 \mathrm{~cm}$ showed a plateau of about $40^{\circ} \mathrm{C}$. No heating was detected with continuous irrigation (Figure 5).

When measuring with a high energy of $1 \mathrm{~J}$, a maximal temperature of $44.2^{\circ} \mathrm{C}$ was detected without irrigation and a distance of $0.5 \mathrm{~cm}$ to the thermometer. A higher distance of $1 \mathrm{cmresulted}$ in a plateau of about $36^{\circ} \mathrm{C}$. No heating was detected with continuous irrigation (Figure 6).

In conclusion the insertion of a DJ with a resulting reduction of the volume in the artificial ureter could raise the maximum temperature of $3^{\circ} \mathrm{C}-4^{\circ} \mathrm{C}$ when using the lower energy setting of $0.6 \mathrm{~J}$ and no irrigation. With the energy setting of $1 \mathrm{~J}$ there is no more relevant difference in the maximum temperature in comparison to the measurement with an empty ureter. However the maximum temperatur plateau is reached slightly faster. With irrigation there is no heating at all (Figure 5 and Figure 6).

In the third setting with direct laser fiber contact to the DJ, a maximal temperature of $46.3^{\circ} \mathrm{C}$ could be reached when measured without irrigation, a distance of $0.5 \mathrm{~cm}$ between the laser fiber and the thermometer and an energy of $0.6 \mathrm{~J}$. When increasing the distance to $1 \mathrm{~cm}$ we had a plateau of $40^{\circ} \mathrm{C}$ with a final maximum of $43^{\circ} \mathrm{C}$. With irrigation no heating was detectable (Figure 7). 


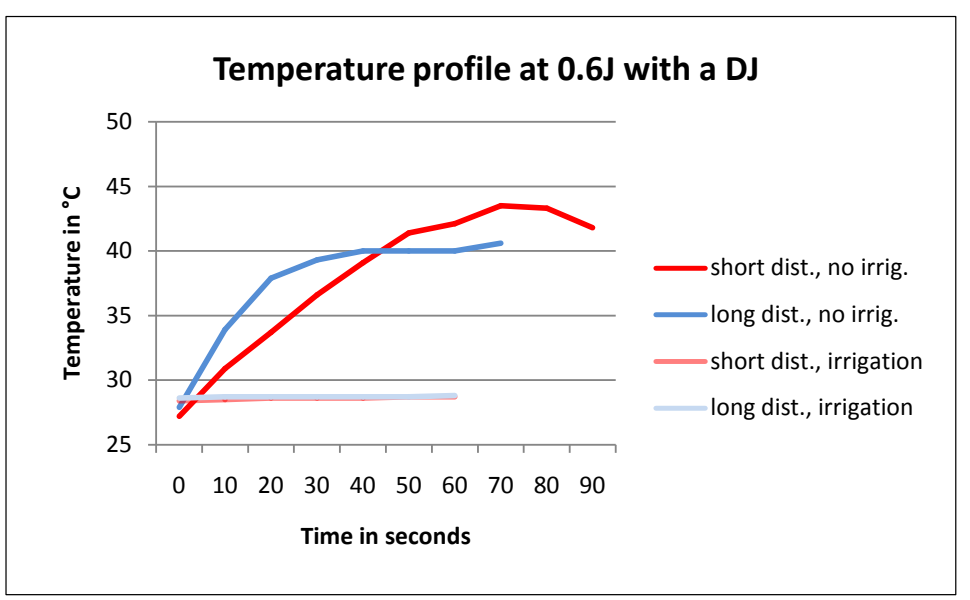

Figure 5. Temperature profile for a measurement with pulse energy of 0.6 $\mathrm{J}$ in a ureter next to a DJ with 4 different settings (short dist. irrigation is behind long dist. irrigation).

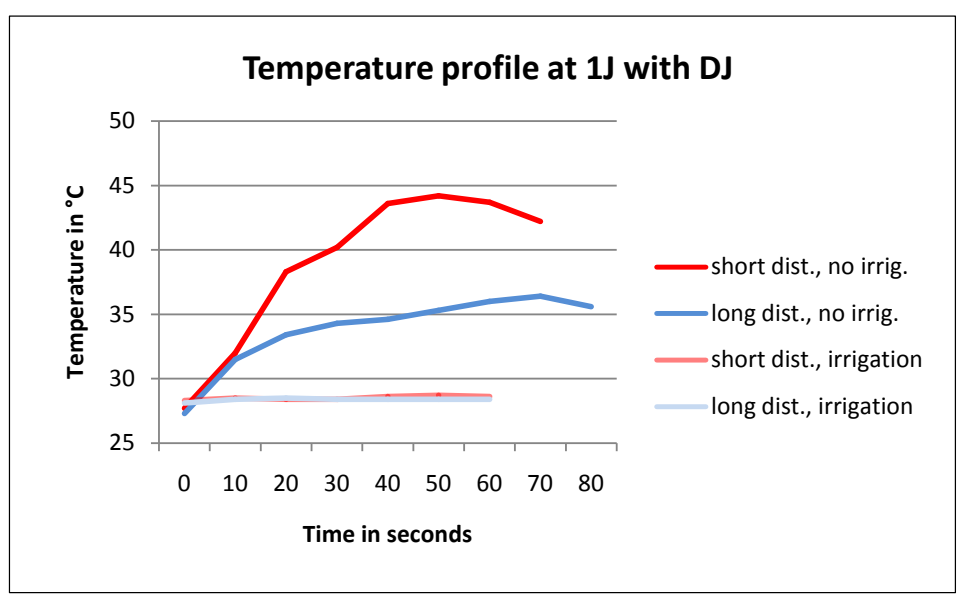

Figure 6. Temperature profile for a measurement with pulse energy of $1 \mathrm{~J}$ in a ureter next to a DJ with 4 different settings(short dist. irrigation is behind long dist. irrigation).

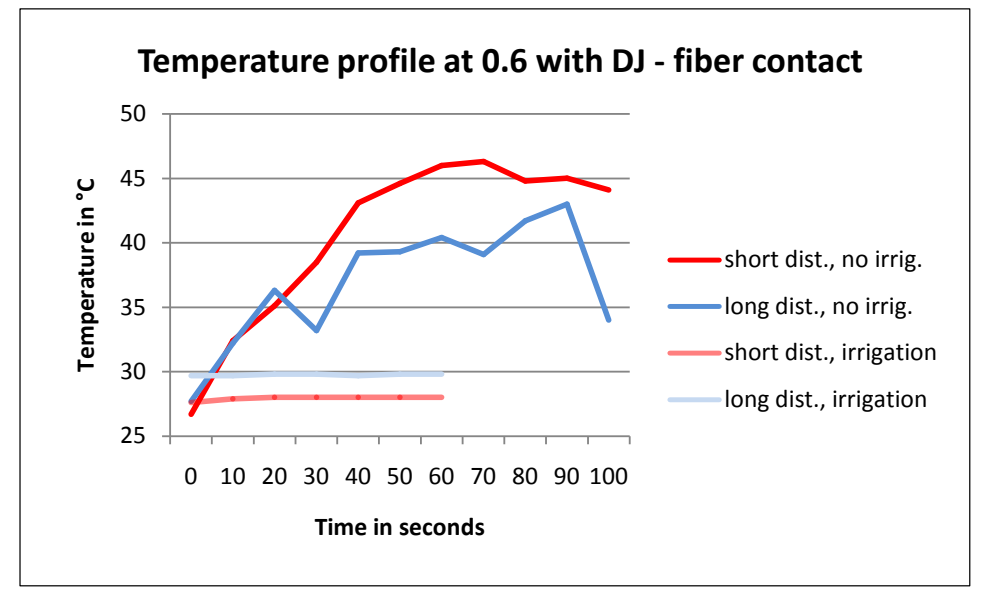

Figure 7. Temperature profile for a measurement with pulse energy of 0.6 $\mathrm{J}$ in a ureter with direct contact between the laser fiber and the DJ with 4 different settings. 
When setting the laser energy to $1 \mathrm{~J}$, maximum temperatures of $52.4^{\circ} \mathrm{C}$ for the short distance measurement and $55.1^{\circ} \mathrm{C}$ for the long distance measurement were detected when using no irrigation. With irrigation no heating was detected at all (Figure 8).

In conclusion it shows that direct contact between the laser fiber and the DJ could raise the maximum temperature by $2.8^{\circ} \mathrm{C}$ when using a pulse energy of $0.6 \mathrm{~J}$ and no irrigation. When using a pulse energy of $1 \mathrm{~J}$ there is a temperature increase of $10.9^{\circ} \mathrm{C}$ in the maximum. With irrigation there is no heating at all (Figure 7 and Figure 8).

Figure 9 shows the setup before laser exposure (Part A) and after laser exposure (Part B). It is clearly visible that a lot of material was removed, presumably burned, by the laser. The burning of material causes heating effects and explains the highest maximum temperature out of all settings. The laser fiber has to be guided along the DJ during laser exposure to assure steady contact with the DJ.

A rising bubble formation was visible when a DJ is inserted and has direct contact to the laser fiber and there is no irrigation. The fast alteration of the temperatures in this setting are caused by the fact that it is not easy for the surgeon to hit the DJ with the laser fiber all the time, since a lot of material is burned and the laser fiber has to be readjusted frequently.

When comparing the maximum temperatures of all settings at a short distance of $0.5 \mathrm{~cm}$, it is visible that there are significant temperature differences between the single settings. Despite the discordant value when measuring the maximum temperature of an empty ureter at a high pulse energy of $1 \mathrm{~J}$, Figure 10 shows that a reduction of the volume and the direct contact to the DJ even to a greater degree, leads to an increase of the maximum temperature.

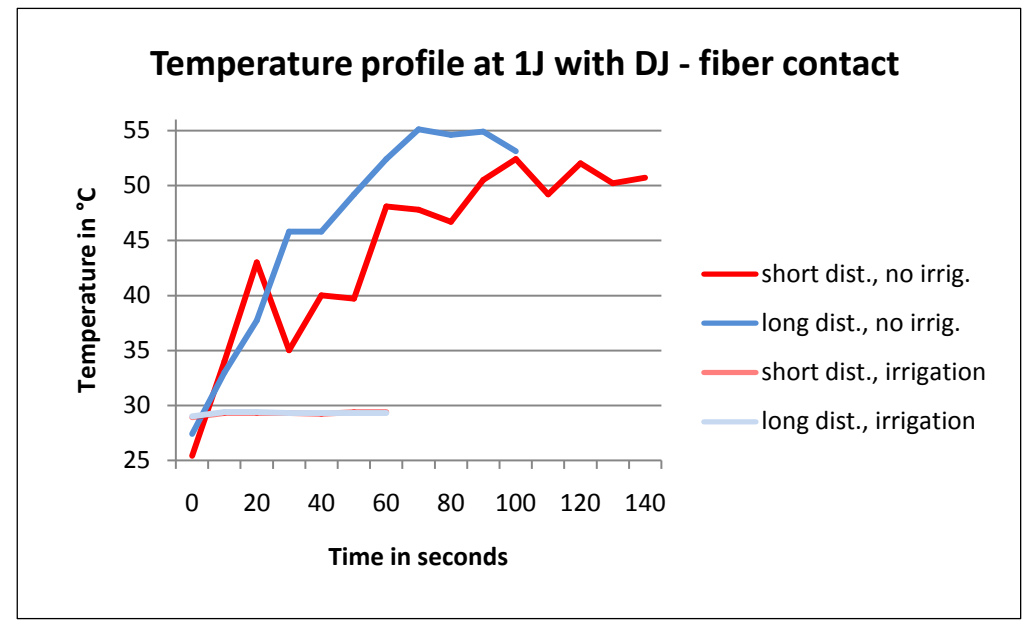

Figure 8. Temperature profile for a measurement with pulse energy of $1 \mathrm{~J}$ in a ureter with direct contact between the laser fiber and the DJ with 4 different settings (short dist. irrigation is behind long dist. irrigation).

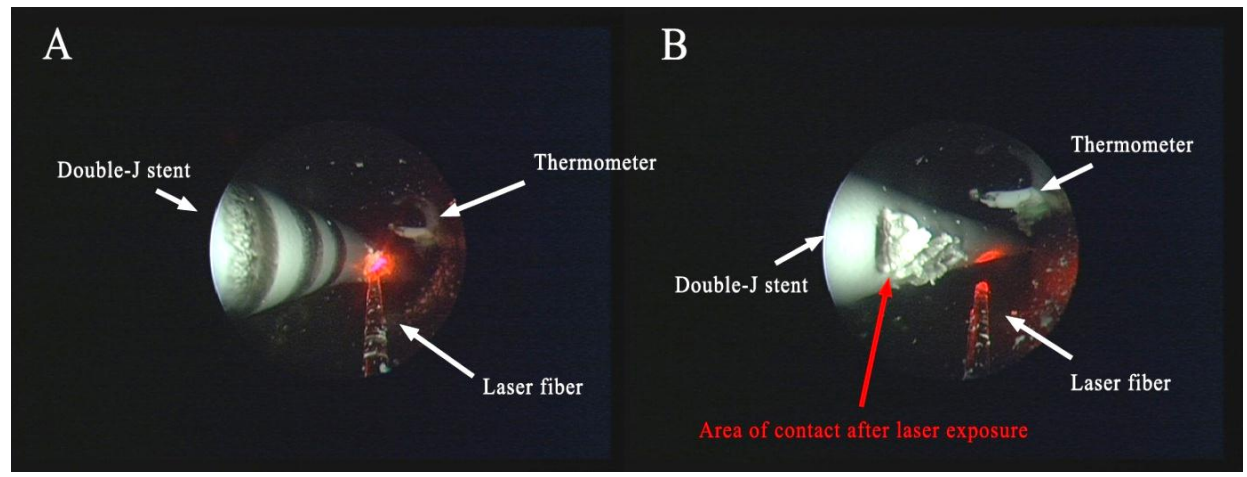

Figure 9. View from inside the catheter through the renoscope. The tip of the thermometer, the DJ and the laser fiber are marked. Part A shows the laser fiber on contact with the DJ. Part B shows the exact spot after laser exposure. 


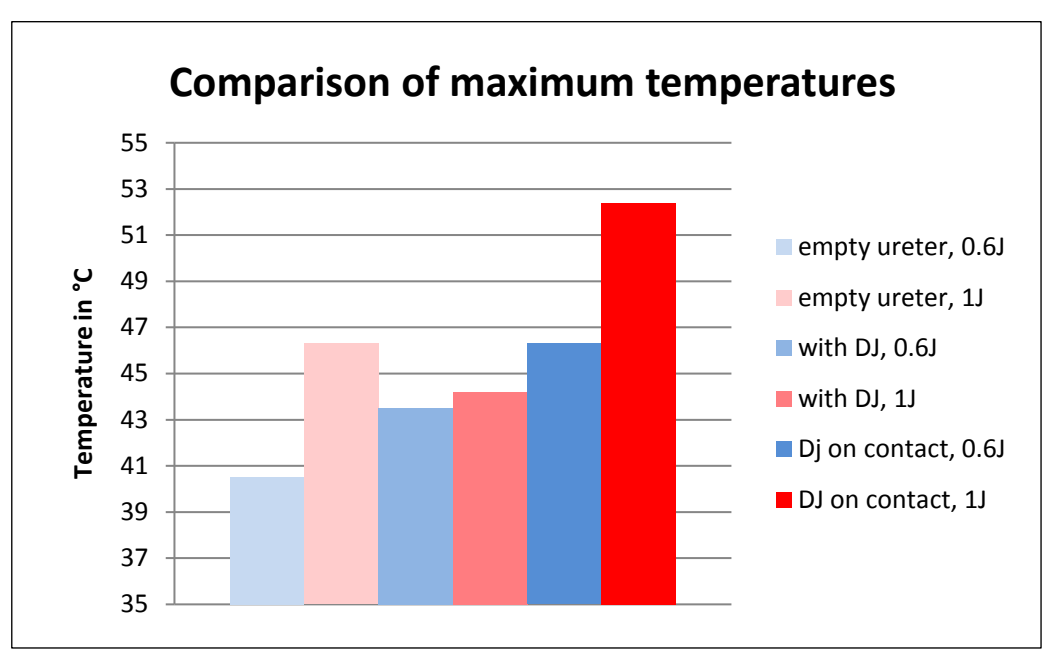

Figure 10. The maximum temperatures compared to each other at a short distance of $0.5 \mathrm{~cm}$ between the laser fiber and the thermometer.

\section{Discussion}

In this study we could confirm that irrigation is a very important factor in preventing the ureter from heating. Also higher energy settings, an inserted DJ or a direct contact between the laser fiber and the DJ couldn't raise the temperature when there is an irrigation.

Without irrigation one could state that a higher energy level rises the temperature in an empty ureter up to $5^{\circ} \mathrm{C}$. With an inserted DJ, the lower pulse energy $(0.6 \mathrm{~J})$ measurement results in same maximum temperature like the high pulse energy measurement without a DJ. Hence the volume reduction caused by the insertion of the DJ has the same heating effect as an elevation of $0.4 \mathrm{~J}$ of the pulse energy when measured without irrigation. This result is congruent with our first intraluminal measurement in which we used an artificial ureter with a diameter of $4 \mathrm{~mm}$ and a pulse energy of $0.6 \mathrm{~J}[8]$. The maximum temperature plateau of that study was reached at $50^{\circ} \mathrm{C}$.

In the third setting, where we exposed the laser light directly on the DJ, we got the highest temperatures of up to $55^{\circ} \mathrm{C}$. We assume there must be a melting or burning of the DJ which let the temperature rise again.

Bubble formation in the artificial ureter always was a sign of heating in every setting without irrigation.

The limitation of this study is the open system of the katheter. In the normal ureteral tract, the ureter ends in the kidney in a blind way. Our lumen of the ureter was relatively big and would normally be adilated ureter. In our experiment were no cooling effects which would normally be done by the blood vessels.

There are several aspects of heat action on biological tissues. There is already adirect cellular destruction at temperatures from $41^{\circ} \mathrm{C}$ to $47^{\circ} \mathrm{C}$ with a exponentially enhancement above $43^{\circ} \mathrm{C}$ [9]-[11]. Further studies should measure the temperature profile beside a real Litotripsy in a patient with a slim Thermometer as they used for ablation in cardiology.

\section{Conclusions}

There is no relevant heating of the ureter when using irrigation.

A decrease of volume by adding a DJ in the artificial ureter can lead to an increase in the temperature maximum, when the pulse energy is at a relatively low level of $0.6 \mathrm{~J}$ and no irrigation is used. A direct contact between the laser fiber and the DJ seems to cause additional heating because of melting or underwater burning of the DJ.

\section{References}

[1] Koch, H., Brenner, G. and Kerek-Bodden, H. (2007) Die 50 häufigsten Diagnosestellungen (ICD-10 Schlüsselnummern) des Gesamtjahres 2006 für 12 ausgewählte Fachgebiete. Zentralinstitut für die Kassenärztliche Versorgung in der Bundesrepublik Deutschland, 15.

[2] Bichler, K., Strohmeier, W.L., Eipper, E. and Lahme, S. (2007) Epidemiologie. In: Bichler, K., Ed., Das Harnstein- 
leiden, GEK-Edition, 31-44.

[3] Rosette, J., Denstedt, J., Geavlete, P., Keeley, F., Matsuda, T., Pearle, M., Preminger, G. and Traxer, O. (2014) The Clinical Research Office of the Endourological Society Ureteroscopy Global Study: Indications, Complications and Outcomes in 11,885 Patients. Journal of Endourology, 28, 131-139. http://dx.doi.org/10.1089/end.2013.0436

[4] Marks, A.J. and Teichman, J.M. (2007) Lasers in Clinical Urology: State of the Art and New Horizons. World Journal of Urology, 25, 227-233. http://dx.doi.org/10.1007/s00345-007-0163-x

[5] Piergiovanni, M., Desgrandchamps, F., Cochand-Priollet, B., et al. (1994) Ureteral and Bladder Lesions after Ballistic, Ultrasonic, Electrohydraulic, or Laser Lithotripsy. Journal of Endourology, 8, 293-299. http://dx.doi.org/10.1089/end.1994.8.293

[6] Molina, W.R., Silva, I.N., Donalisio da Silva, R., Gustafson, D., Sehrt, D. and Kim, F.J. (2014) Influence of Saline on Temperature Profile of Laser Lithotripsy Activation. Journal of Endourology, 26.

[7] Cordes, J., Lange, B., Jocham, D. and Kausch, I. (2011) Destruction of Stone Extraction Basket during an in Vitro Lithotripsy-A Comparision of Four Lithotripters. Journal of Endourology, 25, 1-4. http://dx.doi.org/10.1089/end.2011.0019

[8] Cordes, J., Nguyen, F. and Sievert, K.-D. (2015) First Intraluminal Temperture Measurement during Ho:YAG-Laser Exposure at an in-Vitro URS. OJU, 5, 1-5. http://dx.doi.org/10.4236/oju.2015.51001

[9] Teichman, J.M., Vasser, G.J. and Glickman, R.D. (1998) Holmium:Yttrium-Aluminum-Garnet Lithotripsy Efficiency Varies with Stone Composition. Urology, 52, 392-397. http://dx.doi.org/10.1016/S0090-4295(98)00239-8

[10] Welch, A.J. and van Gemert, M.J.C. (1995) Optical-Thermal Response of Laser-Irradiated Tissue. New York Plenum Press. http://dx.doi.org/10.1007/978-1-4757-6092-7

[11] Urano, M., Kuroda, M.F. and Nisimura, Y., et al. (1999) For the Clinical Application of Thermalchemotherapy Given at Mild Temperatures. North American Hyperthermia Group, 15, 79-107. http://dx.doi.org/10.1080/026567399285765 